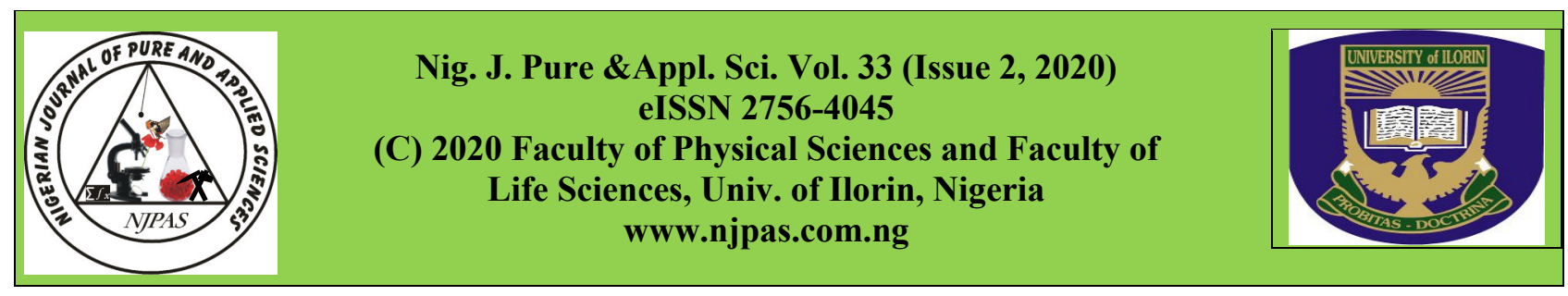

\title{
http://dx.doi.org/10.48198/NJPAS/20.A06
}

\section{Quantification of the Probability of Exposure of Humans to Pathogenic Microbes Present in Some Ready-To-Eat Foods Served in Nigerian Restaurants}

${ }^{1}$ Department of Biological Sciences, College of Natural and Applied Sciences, Igbinedion University Okada, Edo State, Nigeria

\begin{abstract}
Foodborne diseases have become global public health problems. Some ready-to-eat (RTE) foods, particularly vegetable salads, are generally considered as high-risk foods because they often harbour myriad of microbial pathogens. Therefore, this research aimed to evaluate the probability of exposure of humans to pathogenic microbes in RTE salads and fufu served in Nigerian restaurants. Isolation of bacteria in the samples was carried out with the pour plate technique. Identification of bacterial colonies was performed with phenotypic methods and $16 \mathrm{~S}$ rRNA gene analysis. The parasitological examination was performed with zinc sulphate centrifugal floatation method. Overall mean aerobic plate counts (APC) of salad and $f u f u$ samples were $7.10 \pm 6.69 \log _{10}$ $\mathrm{CFU} / \mathrm{g}$ and $3.67 \pm 2.77 \log _{10} \mathrm{CFU} / \mathrm{g}$ respectively; while mean total coliform counts (TCC) were respectively $6.45 \pm 5.90 \log _{10} \mathrm{CFU} / \mathrm{g}$ and $2.46 \pm 1.90 \log _{10} \mathrm{CFU} / \mathrm{g}$. Bacterial counts seen in salad samples were statistically significantly different $(p=0.009 ; \alpha=0.05$ for APC and $p=0.001 ; \alpha=0.05$ for TCC) from those recorded in $f u f u$ samples. The increasing order of human exposure to specific microbial genera present in the salad samples is Ascaris-Citrobacter-Serratia-Entamoeba-Staphylococcus- Pseudomonas- Bacillus- Proteus. Humans were only exposed to Bacillus species in fufu samples because most of the microbes that were found in salads were not present in $f u f u$. Thus, it is recommended that sellers and food handlers of RTE foods, particularly the RTE salads, should routinely decontaminate and properly handle the vegetable ingredients used in preparing salads.
\end{abstract}

Keywords: Foodborne disease, high-risk foods, RTE salad, $f u f u$, microbes, exposure

\section{Introduction}

Foodborne illnesses cause considerable health burden annually which translates to huge loss in economic terms (Hanson et al., 2012; WHO, 2015; Hoelzer et al., 2018). A significant proportion of the health burden occurs in developing countries due to unhygienic conditions (WHO, 2015). Two foods, namely ready-to-eat salad and ready-to-eat fermented cassava dough (locally referred to as $f u f u$ ), frequently consumed in Nigeria were evaluated in this study.
RTE salad is a term that refers to a mixture of cream and sliced fruit and vegetables (Halablab et al., 2011; Uwamere et al., 2013). RTE salads often require no heating before consumption, thus, making them high-risk foods (Nesbitt et al., 2009; Hannan et al., 2014). RTE salads are termed high-risk foods because the fruit and vegetables which served as the major ingredients harboured an array of pathogenic microbes (Udo et al., 2009; Mir et al., 2018) due to their direct contact with soil, water and dust (Falomir et al., 2010; Ilyas et 
al., 2016; Manyi-Loh et al., 2018). These ingredients make salads unfit for consumption, especially when applied in preparing salad without sufficient washing. Filthy utensils and improper personal hygiene of handlers are the Page | 3721 other routes of salad contamination (Rodríguez-Caturla et al., 2014).

RTE $f u f u$ is a product of submerged fermentation of mashed cassava tubers. Fufu is often wrapped in polythene nylon and served with vegetable soup (Inetianbor et al., 2017). The growth of microbes in $f u f u$ is not normally favoured by the processing techniques used in fufu production (Inetianbor et al., 2017). Hence post-processing contamination, most likely, may be attributed to the diversity of microbes present in the fufu.

The myriads of pathogenic microbes present in salads that humans are exposed to have been reported in several studies. Some of these microbes include Klebsiella species, Salmonella typhi, Staphylococcus aureus, Escherichia coli, Enterobacter species, Pseudomonas aeruginosa, Yersinia enterocolitica, Serratia species, Providencia species, Shigella sonnei, Citrobacter freundii, Proteus species, Bacillus species and Aeromonas hydrophila (Uwamere et al., 2013; Mir et al., 2018). Odom et al. (2012) also indicated in their studies that humans were exposed to microbes, such as Bacillus, Corynebacterium, Staphylococcus, Enterobacter, Citrobacter, Lactobacillus, Candida and Saccharomyces species in fufu. However, there exists a dearth of data on the probability of exposure of human consumers to myriads of microbes in RTE foods. Hence this research aimed to evaluate the probability of exposure of humans to pathogenic microbes in the RTE salads and $f u f u$ served in Nigerian restaurants.

\section{Materials and Methods}

Experimental design

This study was carried out in Igbinedion University, Okada, Edo State, Nigeria from March 2019 to October 2019. Six hundred and forty RTE salad samples prepared using cabbage, lettuce, cucumber, carrots and cream were obtained from 64 restaurants situated in Oredo, Ikpoba-Okha, Egor and Ovia-North East Local Government areas of Edo State, South Southern Nigeria. Ten RTE salad samples were randomly obtained from each restaurant (sampling location) for bacterial analysis, thus, constituting a total of 640 RTE salad samples collected from the 64 selected sampling locations. The randomization was implemented with the Wei's Urn iterative randomization protocol (Rosenberger and Lachin, 2002). Microbial counts and prevalence data were collated and then converted to continuous variables. The measurements that were performed include aerobic plate count (APC) and total coliform count (TCC). Parasitological examination of the food samples was also performed. Statistical significance in the variability of the value of the mean or median of APC and TCC obtained from the RTE food samples collected from four different local government areas was estimated with the one-way analysis of variance (ANOVA). The outcome of Shapiro-Wilk test and Levene test of homogeneity, which determined the normality and homoscedasticity of APC and TCC datasets, was used to determine the preferred ANOVA (parametric [Fisher] test or non-parametric [Kruskal-Wallis] test). Student's t-test was also applied to measure statistical significance in the mean of APC and TCC of RTE salad and fufu samples served in the restaurants. The probability of exposure of human consumers to specific microbes in the RTE foods was mathematically derived from the prevalence of the microbiallycontaminated RTE foods examined (FDA/CFSAN/JIFSAN/RSI 2017).

\section{Isolation and enumeration of bacteria}

RTE salad and $f u f u$ samples from the selected restaurants were put in sterile containers, stored in ice-bags and sent to the Microbiology Laboratory, Igbinedion University, Nigeria for bacterial analysis that commenced within three hours of 
sample collection. Isolation and subsequent bacterial counts to obtain TVC and TCC were done with the pour plate technique (Public Health England, 2014). RTE salads examined in this study were those that were done by mixing cream

Page | 3722 (Mayonnaise, Heinz or BAMA brands) and sliced cabbage, lettuce, carrot and cucumber. Twentyfive grams portion of each sample was mixed with $225 \mathrm{ml} 1.5 \% \mathrm{~W} / \mathrm{V}$ sterile peptone water to make $10^{-1}$ dilution of the sample. Serial dilutions up to $10^{-6}$ were subsequently prepared. One millilitre of the diluted sample was separately mixed with 15 $\mathrm{ml}$ sterile nutrient agar and MacConkey agar media in sterile duplicate Petri dishes to respectively obtain the APC and TCC after an incubation period of 24 hours at $37^{\circ} \mathrm{C}$. After incubation, suitable Petri plates from different dilutions were selected and bacterial colonies were counted with a colony counter. The APC and TCC were expressed as colony-forming units per gram (CFU/g) of the sample.

\section{Genus-level identification of bacterial colonies}

The phenotypic techniques employed for genuslevel identification of representative bacterial isolates was carried out with standard methods (Barrow and Feltham, 2003). The tests performed include Gram-stain, coagulase, catalase, oxidase, urease, indole production, citrate utilization, methyl red (MR) and Voges Proskauer (VP) including lactose and mannitol utilization.

\section{Species-level identification of bacterial colonies}

Species-level identification employed a technique which involved partial 16S rRNA gene analysis that was performed with polymerase chain reaction (PCR) and sequencing methods (Lane, 1991; Schuurman, et al. 2004). Ultrapure DNA templates were extracted with the Zymo-Spin column according to the manufacturer's specification (Zymo Research Corporation, USA). The ultrapure DNA templates were then employed for polymerase chain reaction (PCR) and sequencing. Universal 16S rRNA bacterial primers
(27F [forward primer]: AGA GTT TGA TCM TGG CTC AG; 1492R [reverse primer]: GGT TAC CTT GTT ACG ACT T) often employed for bacterial taxonomy were used to detect the $16 \mathrm{~S}$ rRNA gene. The PCR protocol was performed with a $50 \mu \mathrm{l}$ reaction mixture containing $2 \mu \mathrm{L}$ of template DNA, 10mM Tris-HCL ( $\mathrm{pH} 8.3$ ), 50mM $\mathrm{KCl}, 2 \mathrm{mM} \mathrm{MgCl} 2,200 \mathrm{mM}$ of deoxynucleoside triphosphates (dNTPs), $2 \mathrm{U}$ of GoTaq Hot Start Polymerase and $0.5 \mu \mathrm{M}$ of each primer. The GeneAmp PCR system $9700 \quad$ (Applied Biosystems) carried out the amplification protocol with the following cycling conditions: initial denaturation at $95^{\circ} \mathrm{C}$ for 120 seconds, followed by 40 cycles, with each cycle consisting of denaturation at $94^{\circ} \mathrm{C}$ for 45 seconds; annealing at $55^{\circ} \mathrm{C}$ for 60 seconds; extension at $72^{\circ} \mathrm{C}$ for 120 seconds and a final extension at $72^{\circ} \mathrm{C}$ for 600 seconds. Ten microliters of the amplicons were analyzed by gel electrophoresis on a $2 \%$ agarose prepared in Tris-Borate-EDTA buffer containing $0.5 \mu \mathrm{g} / \mathrm{ml}$ of ethidium bromide at $100 \mathrm{~V}$ for 60 minutes. DNA bands were subsequently visualized and documented (Applied Biosystems). A molecular marker (100 base pair ladder) was run concurrently. The dideoxy-chain termination method was used for DNA sequencing and the PCR products cleaned with ExoSAP-IT (ThermoFisher Scientific) followed by cycle sequencing with the Big Dye Terminator version 3.1 (Applied Biosystems) and subsequent separation of the products by capillary electrophoresis on an ABI 3730×I DNA analyzer. The sequences were quality checked and proofread with Sequencher version 4.10.1 (Gene Codes Corporation, USA). Comparison of experimentally determined nucleotide sequences against sequence database(rRNA_typestrains/prokaryotic_16S_ribo somal_RNA) was done with BLASTN 2.8.0 + program [National Center for Biotechnology Information (NCBI)] to confirm the bacterial taxonomic classification. 


\section{Parasitological examination}

All RTE salad and $f u f u$ samples were observed for the presence of protozoan parasites with the zinc sulphate centrifugal floatation method as Page | 3723 previously prescribed by Parameshwarappa et al. (2012).

\section{Statistical analysis}

Descriptive statistics of the bacterial count datasets was carried out with NCSS ver. 12 data analysis software. Wei's Urn iterative randomization protocol, Shapiro-Wilk test, Kruskal-Wallis nonparametric test, Levene test of homogeneity and Student's t-test were also performed with the NCSS software.

\section{Results}

\section{Estimation of bacterial exposure in the RTE foods}

Table 1 represents the bacterial exposure (expressed as mean APC) in the RTE salad and fufu samples. The mean APC in the RTE salads ranged from $6.69 \pm 6.38 \log _{10} \mathrm{CFU} / \mathrm{g}$ to $7.30 \pm$ $7.20 \log _{10} \mathrm{CFU} / \mathrm{g}$. Overall (that is, cumulating the APC from all the selected sampling locations), mean APC was estimated at $7.10 \pm 6.69 \log _{10}$ $\mathrm{CFU} / \mathrm{g}$. The APC datasets of RTE salads obtained from all the selected sampling locations was nonnormally distributed $(\mathrm{p}=0.0001 ; \alpha=0.05)$ with equal variances $(p=0.65 ; \alpha=0.05)$. Based on the outcome of the normality and homoscedasticity tests, Kruskal-Wallis test, the preferred ANOVA technique, indicated no significant difference $(\mathrm{p}=$ 0.35; $\alpha=0.05$ ) in the median APC of the RTE salads obtained from the four LGAs selected for this study.

In the RTE $f u f u$ samples, the mean APC was between $3.53 \pm 3.02 \log _{10} \mathrm{CFU} / \mathrm{g}$ and $3.77 \pm 3.27$ $\log _{10} \mathrm{CFU} / \mathrm{g}$. Overall, the APC was estimated at $3.67 \pm 2.77 \log _{10} \mathrm{CFU} / \mathrm{g}$. The APC datasets of the fufu samples was normally distributed $(\mathrm{p}=0.15 ; \alpha$ $=0.05)$ with equal variances $(\mathrm{p}=0.78 ; \alpha=0.05)$.
Fisher (F) test indicated no significant difference $(\mathrm{p}=0.44 ; \alpha=0.05)$ in the mean APC of $f u f u$ samples.

The cumulative APC datasets of both RTE salads and $f u f u$ samples was non-normally distributed ( $\mathrm{p}$ $=0.0000 ; \alpha=0.05)$ with equal variances $(\mathrm{p}=0.26$; $\alpha=0.05)$. Student's t-test showed that there was a statistically significant difference $(\mathrm{p}=0.009 ; \alpha=$ 0.05 ) between the APC values of RTE salads and those of $f u f u$ samples.

Table 2 also represents bacterial exposure (expressed as TCC) in RTE salad and fufu samples. The mean TCC in the salad samples ranged from $6.05 \pm 5.80 \log _{10} \mathrm{CFU} / \mathrm{g}$ to $6.79 \pm$ $6.27 \log _{10} \mathrm{CFU} / \mathrm{g}$. Overall, the TCC was $6.45 \pm$ $5.90 \log _{10} \mathrm{CFU} / \mathrm{g}$. The TCC datasets of the salad samples was non-normally distributed $(\mathrm{p}=0.04 ; \alpha$ $=0.05)$ with equal variances $(\mathrm{p}=0.15 ; \alpha=0.05)$. Kruskal-Wallis test showed no significant difference $(p=0.18 ; \alpha=0.05)$ in the median TCC of the samples.

In fufu samples, the mean TCC ranged from $2.28 \pm$ $1.44 \log _{10} \mathrm{CFU} / \mathrm{g}$ to $2.71 \pm 2.50 \log _{10} \mathrm{CFU} / \mathrm{g}$. Overall, the TCC was estimated at $2.46 \pm 1.90$ $\log _{10} \mathrm{CFU} / \mathrm{g}$. The TCC datasets of fufu samples was non-normally distributed $(\mathrm{p}=0.0001 ; \alpha=$ $0.05)$ with equal variances $(\mathrm{p}=0.28 ; \alpha=0.05)$. Kruskal-Wallis ANOVA test indicated no statistically significant difference $(p=0.73 ; \alpha=$ $0.05)$ in the median TCC of the samples.

The cumulative TCC datasets of both salad and $f u f u$ samples was non-normally distributed $(\mathrm{p}=$ $0.0000 ; \alpha=0.05)$ with unequal variances $(\mathrm{p}=$ $0.002 ; \alpha=0.05$ ). Student's t-test also revealed that there was a statistically significant difference $(\mathrm{p}=$ $0.001 ; \alpha=0.05$ ) between the TCC values of salad and fufu samples.

\section{Identification of the microbes that human consumers were exposed to}

Only Bacillus species was present in the fufu samples, while the array of bacterial genera which 
consist of Proteus, Citrobacter, Bacillus and Serratia including Staphylococcus and Pseudomonas were found in the salad samples. 16S rRNA sequence analysis of some bacterial isolates showed that Proteus vulgaris, Citrobacter Page | 3724 freundii, Bacillus thuringiensis and Serratia marcescens were the main bacteria which were found in the samples. GenBank accession numbers for representative $B$. thuringiensis strain AND 236, P. vulgaris strain ATU 243, C. freundii strain ABC 2 and $S$. marcescens strain ADJ 212 obtained from the salad samples were MN244445, MN244432, MN244431 and MN244456 respectively.

Findings from the parasitological analysis indicated that protozoan parasites were found only in the salad samples. The identity of the parasites was confirmed as Entamoeba and Ascaris species.

\section{Probability of exposure}

The probability of exposure of human consumers to microbes present in RTE foods shown in Table 3 was mathematically derived from the prevalence of contaminated RTE foods served in the restaurants. Human consumers were mostly exposed to Proteus and least exposed to Ascaris species in RTE salads. The increasing order of exposure of the specific microbial genera present in the RTE salads is Ascaris-Citrobacter-SerratiaEntamoeba-Staphylococcus-Pseudomonas-

Bacillus-Proteus. The results also revealed that humans were only exposed to Bacillus species in RTE fufu.

Table 1: Aerobic plate count (APC) obtained from ready-to-eat (RTE) salad and fufu samples

\begin{tabular}{cccccccc}
\hline & \multicolumn{3}{c}{$\begin{array}{c}\text { RTE salad samples } \\
\text { Aerobic Plate Counts (APC) }\end{array}$} & & \multicolumn{3}{c}{$\begin{array}{c}\text { RTE cassava dough (fufu) } \\
\text { Aerobic Plate Counts (APC) }\end{array}$} \\
\cline { 2 - 4 } \cline { 7 - 8 } Sampling locations & $\mathrm{N}$ & $\begin{array}{c}\text { Mean } \pm \text { SE } \\
\left(\log _{10} \mathrm{CFU} / \mathrm{g}\right)\end{array}$ & $\begin{array}{c}95 \% \mathrm{CI} \\
\left(\log _{10} \mathrm{CFU} / \mathrm{g}\right)\end{array}$ & & $\mathrm{N}$ & $\begin{array}{c}\text { Mean } \pm \mathrm{SE} \\
\left(\log _{10} \mathrm{CFU} / \mathrm{g}\right)\end{array}$ & $\begin{array}{c}95 \% \mathrm{CI} \\
\left(\log _{10} \mathrm{CFU} / \mathrm{g}\right)\end{array}$ \\
\hline Oredo LGA & 160 & $6.74 \pm 5.90$ & $5.66-7.82$ & & 160 & $3.61 \pm 2.71$ & $3.02-4.20$ \\
Ikpoba-Okha LGA & 160 & $7.29 \pm 7.20$ & $6.00-8.58$ & & 160 & $3.73 \pm 2.91$ & $3.11-4.35$ \\
Egor LGA & 160 & $7.30 \pm 7.09$ & $6.03-8.57$ & & 160 & $3.77 \pm 3.27$ & $3.09-4.45$ \\
Ovia North East LGA & 160 & $6.69 \pm 6.38$ & $5.53-7.85$ & & 160 & $3.53 \pm 3.02$ & $2.89-4.17$ \\
All sampling locations & 640 & $7.10 \pm 6.69$ & $6.47-7.73$ & & 640 & $3.67 \pm 2.77$ & $3.35-3.99$ \\
\hline
\end{tabular}

$\mathrm{N}$ : total number of samples examined; SE: standard error of mean; CI: confidence interval of mean

Table 2: Total coliform counts (TCC) obtained from ready-to-eat (RTE) salad and $f u f u$ samples

\begin{tabular}{|c|c|c|c|c|c|c|}
\hline \multirow[b]{2}{*}{ Sampling locations } & \multicolumn{3}{|c|}{$\begin{array}{c}\text { RTE salad samples } \\
\text { Total Coliform Counts (TCC) }\end{array}$} & \multicolumn{3}{|c|}{$\begin{array}{l}\text { RTE cassava dough (fufu) } \\
\text { Total Coliform Counts (TCC) }\end{array}$} \\
\hline & $\mathrm{N}$ & $\begin{array}{c}\text { Mean } \pm \text { SE } \\
\left(\log _{10} \mathrm{CFU} / \mathrm{g}\right)\end{array}$ & $\begin{array}{c}95 \% \mathrm{CI} \\
\left(\log _{10} \mathrm{CFU} / \mathrm{g}\right)\end{array}$ & $\mathrm{N}$ & $\begin{array}{c}\text { Mean } \pm \text { SE } \\
\left(\log _{10} \mathrm{CFU} / \mathrm{g}\right)\end{array}$ & $\begin{array}{c}95 \% \mathrm{CI} \\
\left(\log _{10} \mathrm{CFU} / \mathrm{g}\right)\end{array}$ \\
\hline Oredo LGA & 160 & $6.05 \pm 5.80$ & $4.98-7.12$ & 160 & $2.28 \pm 1.44$ & $1.89-2.67$ \\
\hline Ikpoba-Okha LGA & 160 & $6.25 \pm 6.11$ & $5.13-7.37$ & 160 & $2.71 \pm 2.50$ & $2.15-3.27$ \\
\hline Egor LGA & 160 & $6.79 \pm 6.27$ & $5.65-7.93$ & 160 & $2.28 \pm 1.64$ & $1.86-2.70$ \\
\hline Ovia North East LGA & 160 & $6.33 \pm 5.88$ & $5.25-7.41$ & 160 & $2.40 \pm 1.82$ & $1.95-2.85$ \\
\hline All sampling locations & 640 & $6.45 \pm 5.90$ & $5.89-7.01$ & 640 & $2.46 \pm 1.90$ & $2.20-2.72$ \\
\hline
\end{tabular}


Table 3: Probability of exposure of human consumers to specific microbes present in the contaminated ready-to-eat (RTE) foods

Page | 3725

\begin{tabular}{|c|c|c|c|c|}
\hline \multirow[t]{2}{*}{ Specific microbial species } & \multicolumn{2}{|c|}{ RTE salad $(\mathrm{N}=640)$} & \multicolumn{2}{|c|}{ RTE fermented cassava dough [fufu] $(\mathrm{N}=640)$} \\
\hline & $\begin{array}{c}\text { Mean } \pm \text { SE } \\
(\%)\end{array}$ & $\begin{array}{c}95 \% \mathrm{CI} \\
(\%)\end{array}$ & $\begin{array}{c}\text { Mean } \pm \text { SE } \\
(\%)\end{array}$ & $\begin{array}{c}95 \% \mathrm{CI} \\
(\%)\end{array}$ \\
\hline Pseudomonas & $25.94 \pm 1.73$ & $22.55-29.33$ & $0.00 \pm 0.00$ & $0.00-0.00$ \\
\hline Staphylococcus & $12.03 \pm 1.29$ & $9.50-14.56$ & $0.00 \pm 0.00$ & $0.00-0.00$ \\
\hline Serratia & $7.97 \pm 1.07$ & $5.87-10.07$ & $0.00 \pm 0.00$ & $0.00-0.00$ \\
\hline Proteus & $88.91 \pm 1.24$ & $86.48-91.34$ & $0.00 \pm 0.00$ & $0.00-0.00$ \\
\hline Bacillus & $45.94 \pm 1.97$ & $42.08-49.80$ & $22.65 \pm 1.66$ & $19.40-25.90$ \\
\hline Citrobacter & $4.53 \pm 0.82$ & $2.92-6.14$ & $0.00 \pm 0.00$ & $0.00-0.00$ \\
\hline Ascaris & $1.88 \pm 0.54$ & $0.82-2.94$ & $0.00 \pm 0.00$ & $0.00-0.00$ \\
\hline Entamoeba & $11.09 \pm 1.24$ & $8.66-13.52$ & $0.00 \pm 0.00$ & $0.00-0.00$ \\
\hline
\end{tabular}

$\mathrm{N}$ : total number of samples examined; SE: standard error of mean; CI: confidence interval of mean

\section{Discussion}

Foodborne diseases have become an aggravating health burden with attendant personal and social distress (Scharff, 2012). Unlike RTE fufu, the bacterial load recorded for RTE salads in this study were grossly at unacceptable levels (Table 1). This is due to the favourable environment within the salads suitable for the propagation of bacteria. Hannan et al. (2014), Adirah et al. (2013) as well as Najafi and Bahreini (2012) have reported similar findings in their studies that were respectively carried out in Pakistan, Togo and Iran. The high APC recorded for RTE salad samples could be reflective of the high exposure of the salads to contamination. The high APC in the salads could also suggest that the salads were stored at holding temperatures which favoured the propagation of bacteria (James and Ngarmsak, 2011). The relatively low APC in the RTE fufu may be as a result of the high acidic level in the fufu that was sufficient to eliminate most of the microbes (Odom et al., 2012). The low APC numbers in the fufu may also indicate the negligible impact of postprocessing contamination on the fufu.
Halablab et al. (2011) reported that TCC was considered as a hygiene indicator, especially for faecal contamination. In this study, the TCC was high (Table 2) in the salads suggesting that the vegetables used in the salad preparation were highly contaminated.

The detection of coagulase-positive Staphylococcus in the salads (Table 3 ) could be as a result of cross-contamination from the handler's skin. This is of significant health consequence because this bacterium is a dominant human pathogen which has been reported as an etiologic agent of many clinical infections (Tong et al., 2015). Findings from this study (Table 3) also showed that in the RTE salads, human consumers were mostly exposed to Proteus and least exposed to Ascaris species. The detection of Proteus may have significantly accounted for the high TCC seen in RTE salads and therefore, mainly responsible for contamination of the salads.

\section{Conclusions}

This research revealed the relatively high hazard associated with RTE salads in relation to fufu due to the high microbial load harboured in the RTE 
salads. It also confirmed that the microbial quality of RTE salads available to the public is significantly unsatisfactory as foods must be free from contaminations as much as possible. The persistence of these microorganisms which are Page | 3726 often part of the epiphytic flora of the fruit and vegetables used in preparing salads is a reflection of the poor hygienic practices in the restaurants.

\section{Conflict of Interest:}

None declared.

\section{References}

Adjrah, Y., Soncy, K., Anani, K., Blewussi, K., Karou, D. S., Ameyapoh, Y., de Souza, C. and Gbeassor, M. (2013). Socio-economic profile of street food vendors and microbiological quality of RTE salads in Lome. International Food Research Journal, 20: $65-70$.

Barrow, G.I. and Feltham, R. K. A. (2003). Cowan and Steel's Manual of Medical Bacteria ( $3^{\text {rd }}$ edn). London:

Cambridge University Press.

Falomir, M. P., Gozalbo, D. and Rico, H. (2010). Coliform bacteria in fresh vegetables: from cultivated lands to consumers. Current Research, Technology and Education Topics in Applied Microbiology and Microbial Biotechnology, 2: 1175 - 1181.

Food and Drug Administration, Center for Food Safety and Applied Nutrition, Joint Institute for Food Safety and Applied Nutritiuon, and RiskSciences International (FDA/CFSAN/JIFSAN/RSI) (2017). FDAiRISK ${ }^{\circledR}$ version 4.0 Technical Document. United States: College Park, Maryland.

Halablab, M. A.,Sheet, I. H. and Holail, H. M. (2011). Microbial quality of raw vegetables grown in Bekaa valley, Lebanon. American Journal of Food Technology, 6: 129 - 139.
Hannan, A., Rehman, R., Saleem, S., Khan, M. U., Qamar, M.U. and Azhar, H. (2014). Microbiological analysis of RTE salads available at different outlets in Lahore, Pakistan. International Food Research Journal, 21: 1797 - 1800.

Hanson, L. A., Zahn, E. A., Wild, S. R., Döpfer, D., Scott, J. and Stein, S. (2012). Estimating global mortality from potentially foodborne diseases: an analysis using vital registration data. Population Health Metrics, 10: 5 - 11.

Hoelzer, K., Switt, A. I. M., Wiedmann, M., and Boor, K. J. (2018). Emerging needs and opportunities in foodborne disease detection and prevention: From tools to people. Food Microbiology, 75: $65-71$.

Ilyas, S., Qamar, M. U., Rasool, M. H., Abdulhaq, N. and Nawaz, Z. (2016) Multidrug-resistant pathogens isolated from RTE salads available at a local market in Pakistan. British Food Journal, 118:2068 2075.

Inetianbor, J. E., Ikenebomeh, M. J. and Udochukwu, U. (2017). Microbiological quality of commercially RTE fufusold in Benin City, Nigeria. American Journal of Food,Nutrition and Health, 2: 26 - 30.

James, J. B. and Ngarmsak, T. (2011). Processing of fresh cut tropical fruits and vegetables: A technical guide. Bangkok: FAO.

Lane, D. J. (1991). 16S/23S rRNA sequencing. In nucleic acid techniques in bacterial systematics, eds. Stackebrandt, E. and Goodfellow, M., New York: John Wiley and Sons.

Manyi-Loh, C., Mamphweli, S., Meyer, E. and Okoh, A. (2018). Antibiotic use in agriculture and its consequential resistance 
in environmental sources: potential public health implications. Molecules, 23: 795.

Mir, S. A., Shah, M. A., Mir, M. M., Dar, B. N., Greiner, R. and Roohinejad, S. (2018). Microbiological contamination of RTE vegetable salads in developing countries and potential solutions in the supply chain to control microbial pathogens. Food Control, 85: 235 - 244.

Najafi, M. B. H. and Bahreini, M. (2012). Microbiological quality of mixed fresh-cut vegetable salads and mixed RTE fresh herbs in Mashhad. International Conference on Nutrition and Food Sciences, 39: 62 66.

Nesbitt, A., Shannon, M., Rita, F., Barbara, M., Frank, P., Jan, S., Carl, R., Jeff, W. and Nancy, S. (2009). High-risk food consumption and food safety practices in a Canadian community. Journal of Food Protection, 72: 2575 - 2586.

Odom, T. C., Udensi, E. A. and Nwanekezi, E. C. (2012).Microbiological qualities of hawked retted cassava fufu in Aba Metropolis of Abia State. Nigerian Food Journal, 30: 53 - 58 .

Parameshwarappa, K. D., Chandrakanth, C. and Sunil, B. (2012). The prevalence of intestinal parasitic infestations and the evaluation of different concentration techniques of the stool examination. Journal of Clinical and Diagnostic Research, 6: 1188 - 1191.

Public Health England. (2014). Preparation of samples and dilutions, plating and subculture. In Microbiology Services Food Water and Environmental Microbiology Standard Method FNES26 (F2), London: Public Health England.
Rodríguez-Caturla, M. Y., Valero, A., Carrasco, E., Posada, G. D., García-Gimeno, R. M. andZurera, G. (2012). Evaluation of hygiene practices and microbiological status of ready-to-eat vegetable salads in Spanish school canteens. Journal of the Science of Food and Agriculture, 92: 2332 - 2340.

Rosenberger, W. F. and Lachin, J. M. (2002). Randomization in Clinical Trials - Theory and Practice. New York: John Wiley and Sons.

Scharff, R. L. (2012). Economic burden from health losses due to foodborne illness in the United States. Journal of Food Protection, 75: 123 - 131.

Schuurman, T., de Boer, R.F., Kooistra-Smid, A.M. and vanZwet, A. A. (2004). Prospective study of use of PCR amplification and sequencing of $16 \mathrm{~S}$ ribosomal DNA from cerebrospinal fluid for diagnosis of bacterial meningitis in a clinical setting. Journal of Clinical Microbiology, 42: 734-740.

Tong, S. Y., Davis, J. S., Eichenberger, E., Holland, T. L. and Fowler, V. G. (2015). Staphylococcus aureus infections: epidemiology, pathophysiology, clinical manifestations and management. Clinical Microbiology Reviews, 28: 603 - 661.

Udo, S., Andy, I., Umo, A. and Ekpo, M. (2009). Potential human pathogens (bacteria) and their antibiogram in RTE salads sold in Calabar, South-South Nigeria. The Internet Journal of Tropical Medicine, 5: 1.

World Health Organization (WHO). (2015). WHO estimates of the global burden of foodborne diseases: foodborne disease burden epidemiology reference group 2007-2015? World Health Organization. 